\title{
A segunda crítica social da Saúde de Ivan Illich
}

\author{
Ivan Illich's second social critique of Health
}

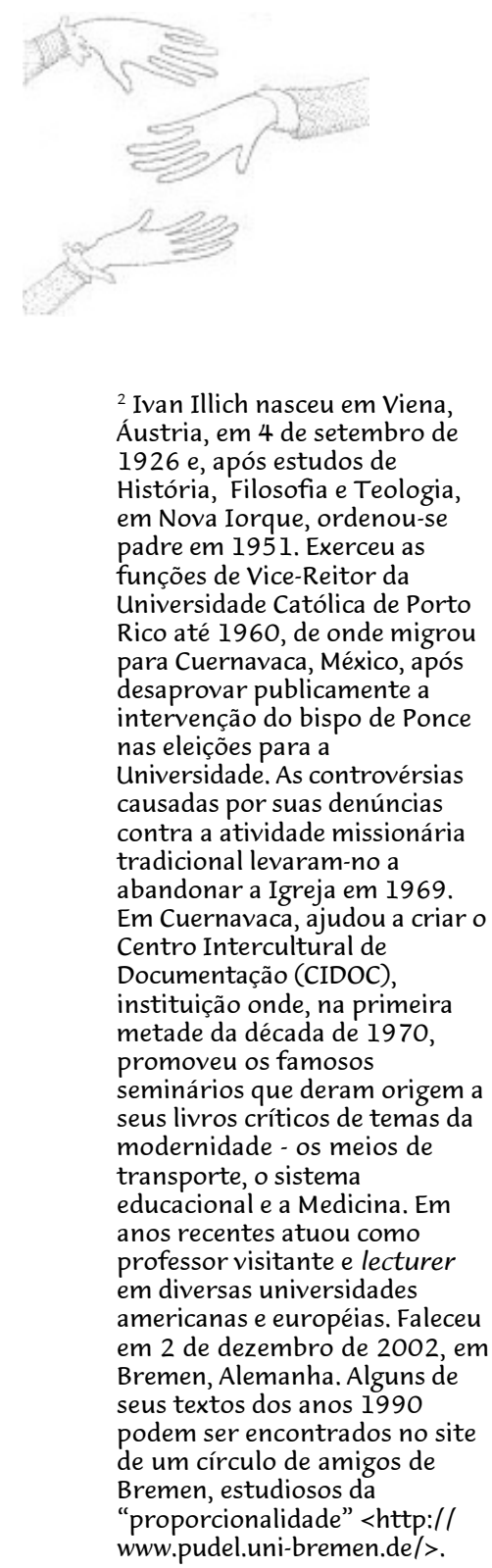

Roberto Passos Nogueira ${ }^{1}$

Na primeira metade dos anos setenta do século passado, um ex-padre austríaco-americano lançava a crítica mais contundente até então empreendida contra a Medicina moderna. Dizia Ivan Illich $^{2}$ (1975, p.1) logo no primeiro parágrafo de sua Nêmesis da Medicina: "a Medicina institucionalizada transformou-se numa grande ameaça à saúde". A versão inicial desse trabalho havia sido escrita em 1973, por ocasião de um período de estudos de Illich em Cuernavaca, no México, e dela apareceram três diferentes edições: Londres (1974), Paris (1975) e Nova Iorque (1976). Na tradução brasileira de 1975, feita com base na edição francesa, lê-se na introdução: " $A$ empresa médica ameaça a saúde, a colonização médica da vida aliena os meios de tratamento, e o seu monopólio profissional impede que o conhecimento científico seja partilhado" (p.1).

Doze anos após haver escrito a versão inicial da Nêmesis, Illich veio a emitir um conjunto de apreciações de sentido fortemente autocrítico em relação à sua obra. Pretendo descrever de forma sucinta neste trabalho os principais argumentos desta segunda crítica social da saúde que passou despercebida no Brasil, como, de resto, tudo que ele veio a escrever após a Nêmesis, obra que definitivamente influenciou a formação intelectual dos que integravam a Saúde Coletiva nos anos setenta.

\footnotetext{
*Texto preparado a partir de Tese de Doutorado (Nogueira, 1999).

${ }^{1}$ Médico, Pesquisador do Núcleo de Saúde Pública da Universidade de Brasília e do Instituto de Pesquisa Econômica Aplicada (IPEA), Brasília, DF. <nogueira@ipea.gov.br>
} 
Faz-se necessário inicialmente revisitar o conceito de iatrogênese, que, segundo o Ivan Illich dos anos setenta, aparece sob três formas principais. Em primeiro lugar, a iatrogênese clínica, causada pelos próprios cuidados de saúde, resultando em danos à saúde atribuíveis à falta de segurança e ao abuso das drogas e das tecnologias médicas mais avançadas. Em segundo lugar, a iatrogênese social, decorrente de uma crescente dependência da população para com as drogas, os comportamentos e as medidas prescritas pela Medicina em seus ramos preventivo, curativo, industrial e ambiental; a iatrogênese social é, ao fim e ao cabo, sinônimo de medicalização social, porque anula o sentido da saúde enquanto responsabilidade de cada indivíduo e de sua família e dissemina na sociedade o "papel de doente", que é um comportamento apassivado e dependente da autoridade médica. Finalmente, Illich identifica uma iatrogênese cultural, que consiste na destruição do potencial cultural das pessoas e das comunidades para lidar de forma autônoma com a enfermidade, a dor e a morte. Neste caso, o que caracteriza o dano é a perda de tudo aquilo que as tradições criaram ao longo dos séculos enquanto expedientes culturais eficazes para enfrentar a vulnerabilidade humana diante de tais contingências da vida. As práticas tradicionais e o saber espontâneo que lhes acompanham foram, nos últimos séculos, substituídos pela figura plenipotente do médico e de sua técnica profissional heterônoma, que trazem a promessa delusória de estender indefinidamente a existência das pessoas.

Em 1985, na Universidade Estadual da Pensilvânia, Illich dizia de maneira autocrítica:

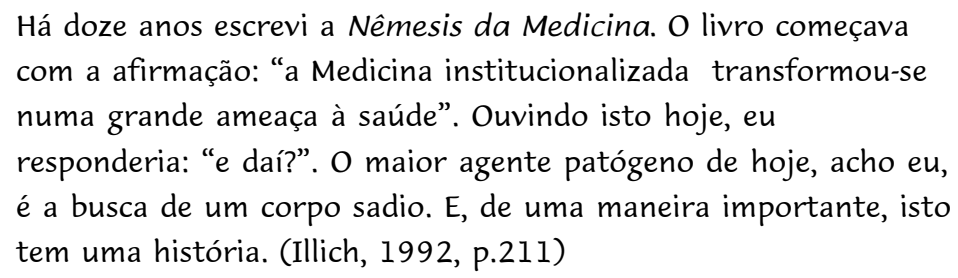

A aguda autocrítica de Illich dirige-se a um ponto de natureza conceitual: a noção de iatrogênese não poderia deixar de partir de uma história do corpo $e$ das práticas a ele relacionadas. Ecoando algumas das teses dos estudos de Rosen (1979) e de Foucault (1977), diz Illich que a história do corpo na modernidade começou com o mercantilismo, coincidindo com a emergência do estado-nação e sua polícia sanitária. O corpo aparece então como imagem coletiva, como quantidade de população produtora e força do exército, tidos então, na ideologia do mercantilismo, como garantias da prosperidade nacional. Mas, posteriormente, o corpo é transformado num objeto portador de um direito individualizado, um direito de felicidade. Mais recentemente, prossegue Illich, o sonho de uma vida ativa ainda na terceira idade e a demanda econômica por trabalhadores produtivos foram fundidos na própria idéia da saúde como direito social. Porém, no ano de 1985, afirma Illich, a saúde vai além de um direito e de uma prerrogativa, pois transformou-se numa necessidade obsessiva que tem de se materializar na experiência do corpo: "para muitos contemporâneos, a busca da saúde

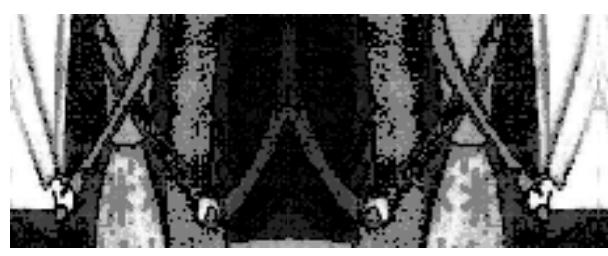


tornou-se consubstancial com a experiência de seus corpos" (Illich, 1992, p.211).

Illich confessa que este importante aspecto da iatrogênese cultural, "a busca patogênica da saúde", havia lhe escapado por completo quando escreveu sua obra famosa. A mania com sua própria condição de saúde corporal ou higiomania, como a denomino num artigo inspirado nas idéias de Illich (Nogueira, 2001), é algo que passou a fazer parte definitivamente do estilo de vida altamente tecnificado da contemporaneidade. Tal estilo de vida, que se funda na idolatria do corpo e da saúde do corpo, não é criado por uma simples expropriação profissional: é alimentado pela mídia, pelas academias de cultura física, pela indústria da "dieta" e pela indústria em geral, $e$, enfim, pelos que estão sempre interessados em vender este novo produto - o auto-cuidado.

Nos anos oitenta, observa Illich, é preciso salientar que não é mais o establishment de saúde que produz a imagem do corpo. A concepção predominante surge agora de uma somatocracia que exalta e promove a industrialização automatizada da produção do corpo:

\footnotetext{
Durante os anos sessenta a profissão médica era proeminente em determinar o que é o corpo e como se deve senti-lo. Nos anos setenta, ela começou a dividir com outros agentes o poder de reificar as pessoas. De um empreendimento que reifica as pessoas como psiques e corpos, um novo modelo surgiu que engendra pessoas que reificam a si mesmas: os que se concebem como “produtores" do seu próprio corpo. (Illich, 1992, p.217)
}

A saúde passa a ter duas vias privilegiadas de acesso e não apenas uma: não só o acesso possibilitado pela Medicina, que ainda se mantém pelo domínio dos profissionais, como também o acesso por meio da cultura do corpo, cada vez mais influente, cultura da qual os médicos são apenas uma reduzida fração entre seus inumeráveis protagonistas. Trata-se de uma produção do corpo em maneira robotizada, automatizada.

Illich não se refere nesse texto aos trabalhos de Foucault sobre a história da sexualidade, que expõe pontos de vista similares. Mas em sua obra anterior sobre gênero (Illich, 1982, p.109) observa que o primeiro volume da História da Sexualidade de Foucault "foi pioneiro no estudo histórico do processo pelo qual o corpo dos sujeitos do novo Estado de Bem-Estar Social foi constituído como objeto de um discurso profissional sobre o corpo dele ou dela". Similarmente a Foucault, Illich conclui pela necessidade de construir uma história do corpo que englobe as ideologias da saúde.

Segundo Illich, é o próprio caráter simbólico da Medicina que muda nos anos setenta e oitenta do século passado. As medicinas alternativas, as concepções ambientalistas, as correntes diversas da auto-ajuda, as modas dietéticas, as práticas de corpo inumeráveis etc. influenciam mais sobre o que o leigo pensa a respeito de saúde do que os próprios médicos.

Naturalmente, a mídia toma um papel proeminente, pois abarca e serve de veículo de difusão a todas essas variadas formas normativas de cuidado do 
cuidado do corpo. Por outro lado, nos aspectos financeiros, verifica-se que os gastos com programas integrais de cuidado com a saúde passam a crescer mais rapidamente do que os gastos com a Medicina. Mais ainda - os recursos para investimentos em segurança, ecologia, educação e defesa civil são facilmente aprovados pelo governo quando seus efeitos sobre a saúde conseguem ser patentemente demonstrados:

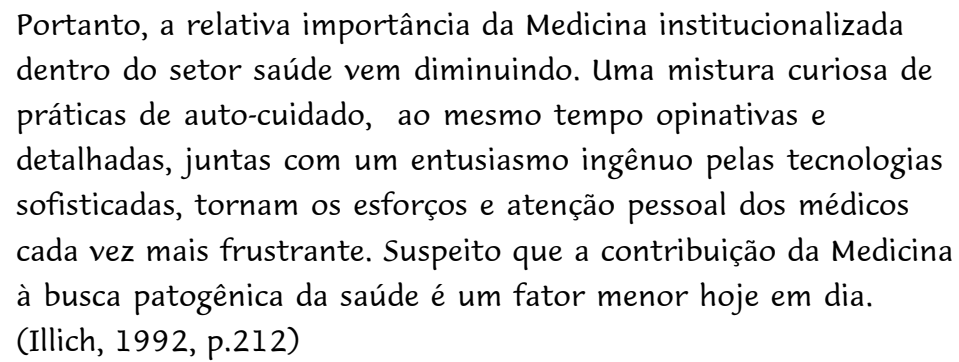

Illich afirma que não está insatisfeito com o texto que escreveu na década anterior, porque seu objetivo era enfocar também certas formas gerais de dano, que advêm, de maneira indireta, da disseminação de crenças e práticas sociais inibidoras da autonomia diante da enfermidade, da dor e da morte. No entanto, lamenta que tenha deixado de enxergar o que seria um efeito simbólico iatrogênico mais profundo: a da iatrogênese do corpo mesmo. Esse fenômeno contemporâneo só pode ser compreendido pela história das mudanças operadas na matriz ("gestalt") de percepção do corpo. A autopercepção do corpo volveu-se iatrogênica, em sua mais recente metamorfose $e$ situa-se agora por relação à emergência de um estilo de vida high-tech e midiático.

\footnotetext{
O poder profissional sobre a definição da realidade atingiu seu clímax e está em declínio agora. Neste momento, uma mistura confusa do high-tech com sabedoria naturalista, bio-engenharia $e$ exercício autônomo operam para criar o sentimento de realidade sentida, inclusive a do corpo. (Illich, 1992, p.217)
}

O que é curioso nessa auto-crítica é que Illich não só indica uma limitação da sua forma de abordagem anterior da iatrogênese, como também parece inverter sua compreensão quanto ao que pode constituir uma forma adequada de evitar seus riscos: as práticas do auto-cuidado passam a ser consideradas parte da iatrogênese gerada pela nova imagem do corpo. Os agentes terapêuticos profissionais podem ser dispensados pelos consumidores que recorrem agora a um saber difuso sobre saúde que a sociedade disponibiliza pelos meios de comunicação. Houve, sim, uma desmedicalização da saúde, mas num processo que é iatrogênico. Illich faz uma interpretação veementemente negativa dessa linha contemporânea de autonomização do cuidado com o corpo. Quando tudo parecia merecer seu endosso diante de uma tendência de ganho de autonomia do sujeito no manejo consciente dos meios para garantir sua saúde, ele institui um novo parâmetro de julgamento: essa autonomia (ou pseudo-autonomia) pode ser 
iatrogênica.

O contexto social que serve de referência teórica a essa segunda crítica da saúde é algo bem distinto do industrialismo que Illich havia analisado na Nêmesis. No final dos anos setenta, Illich (1978) já começara a falar do surgimento de um profissionalismo pós-industrial, que não está mais fundado na detecção $e$ atendimento unilateral das necessidades dos seus clientes. Ele indicava o surgimento de um pósprofissional: alguém que se mostra sensível às falhas e desvios éticos do profissionalismo anterior, que se diz mais atento aos problemas de relacionamento com seus clientes e que propõe a estes seguir variados métodos de auto-ajuda. Há agora uma ênfase muito especial que é posta nos mecanismos de auto-ajuda e ajuda recíproca entre os clientes. Este novo ethos entre os profissionais responde a reclamos da sociedade, que exige uma avaliação leiga dos resultados dos serviços profissionais e dos riscos que introduzem, uma melhor legislação para proteção dos seus interesses como consumidores e a quebra de certos controles corporativos. Aparecem médicos, dentistas, advogados etc. que são mais "conscientes", sensíveis aos problemas econômico-sociais do exercício de suas profissões (dir-se-ia, posteriormente, politicamente corretos).

Diz Illich (1978) que três diferentes estratagemas são usados pelo novo profissionalismo ou pós-profissionalismo:

1) a auto-crítica - os médicos recomendam que, numa grande quantidade de casos de câncer, sejam abandonados os procedimentos habituais de cirurgia, radiação e quimioterapia, visto que essas terapias prolongam $e$ tornam mais agudo o sofrimento dos pacientes, sem que haja uma recompensa em termos de sua sobrevida; conseqüência que Illich visualiza: é preciso ter mais profissionais e organizações específicas para promover a função de auto-vigilância;

2) a coordenação interprofissional - é amplamente divulgado o slogan "é melhor gastar dinheiro para continuar sadio, do que com os médicos quando você se enferma"; isto quer dizer, interpreta Illich, que os profissionais que se beneficiam com a indústria do cuidado com o corpo pretendem que esse dinheiro seja agora gasto com seus serviços;

3) a proteção à auto-ajuda - nos Estados Unidos, de 1965 a 1978, foram escritos nada menos que 2700 livros de auto-ajuda em saúde para que cada um seja seu próprio paciente, "de tal modo que você só consulte um médico quando valer a pena para ele". Interpretação dada por Illich: o cliente foi transformado num profissional a mais e a auto-ajuda tornou-se o novo radical chic das elites de uma sociedade pós-industrial.

Enfim, o conhecimento profissional em saúde tornou-se ardilosamente desmonopolizado e é esta desmonopolização que viabiliza o surgimento do fenômeno social da iatrogênese do corpo.

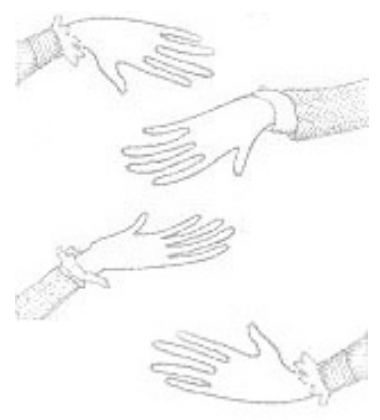

Referências

FOUCAULT, M. Microfísica do poder. São Paulo: HUCITEC, 1977.

ILLICH, I. A expropriação da saúde. Nêmesis da Medicina. Rio de Janeiro: Nova Fronteira, 1975.

ILLICH, I. Toward a history of needs. New York: Random House, 1978. 
ILLICH, I. Gender. Berkeley: Heyday Books, 1982.

ILLICH, I. In the mirror of the past, lectures and adresses, 1978-1990. New York: Marion Boyars, 1992.

NOGUEIRA, R. P. A saúde pelo avesso: uma reinterpretação de Ivan Illich, o profeta da autonomia. Rio de Janeiro, 1999. Tese (Doutorado). Instituto de Medicina Social, Universidade Estadual do Estado do Rio de Janeiro.

NOGUEIRA, R. P. Higiomania: a obsessão com a saúde na sociedade contemporânea. In: VASCONCELOS, E. M. (Org.). A saúde nas palavras e nos gestos: reflexões da rede educação popular e saúde. São Paulo: Hucitec, 2001. p.63-72.

ROSEN, G. Da polícia médica à Medicina Social: ensaios sobre história da assistência médica. Rio de Janeiro: Graal, 1979.

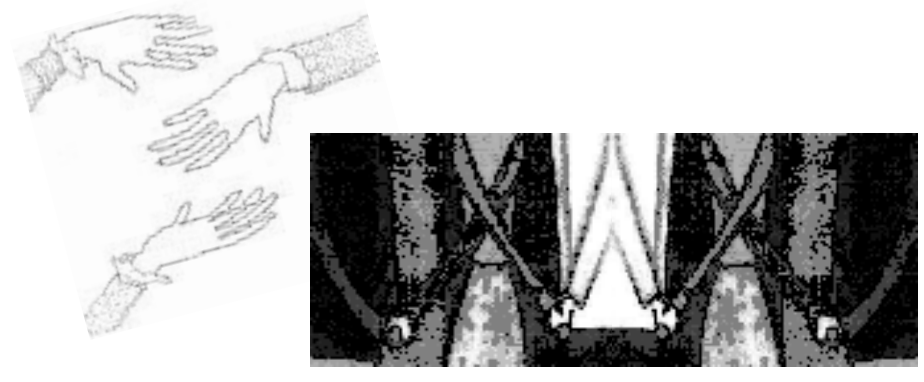

In The Nemesis of Medicine, Ivan Illich displayed the essential elements of his first critique of health, stating that the widespread industrialization of healthcare and the medicalization of life in modern society create several forms of iatrogenesis or damage to health, as a result of people losing the capacity to behave autonomously vis à vis disease, pain and aging. In the second social critique of health, Illich deals with the manifestation of a new social iatrogenesis resulting from a sort of obsession with bodily health and its production through physical activities, diets, etc. in a condition of apparent autonomy. This is "healthy body" consumerism, which responds less to the actions of physicians and more to information publicized by the media and by unofficial therapeutical agents.

KEY WORDS: History; Public Health; Ethics.

Na Nêmesis da Medicina, Ivan Illich expôs os elementos essenciais da sua primeira crítica da saúde, afirmando que a ampla industrialização da saúde e medicalização da vida na sociedade moderna faz aparecer diversas formas de iatrogênese ou danos à saúde, como resultado da perda da capacidade de ação autônoma das pessoas perante a enfermidade, a dor e o envelhecimento. $\mathrm{Na}$ segunda crítica social da saúde, Illich trata do surgimento de uma nova iatrogênese social, a iatrogênese do corpo, que resulta de uma espécie de obsessão com a saúde corporal e com sua produção através de atividades físicas, dietas etc. em aparente condição de autonomia. Trata-se de um consumismo do corpo saudável, que responde menos à ação dos médicos e mais às informações difundidas pelos meios de comunicação e pelos agentes terapêuticos não-oficiais.

PALAVRAS-CHAVE: História; Saúde; Saúde Pública; Ética.

En Nemesis de la Medicina, Ivan Illich expuso los elementos esenciales de su primera crítica de la salud, indicando que una industrialización extensa de la salud y la medicalización de la vida en la sociedad moderna crean varias formas de iatrogénesis o daños a la salud, que resultan de la pérdida de la capacidad de comportamiento autónomo de las personas ante la enfermedad, el dolor y el envejecimiento. En la segunda crítica social de la salud, Illich se ocupa del surgimiento de la iatrogenesis del cuerpo, que es una clase de obsesión con la salud corporal y con su producción a través de actividades físicas, dietas etc. en condiciones aparentes de autonomía. Ésta iatrogenesis es un consumismo del cuerpo saludable y no responde directamente a los comandos y a las intervenciones de los médicos sino que depende de la información que difundida por los medios de comunicación y por los agentes terapéuticos no oficiales.

PALABRAS CLAVE: Historia; Salud; Salud Publica; Etica. 